\title{
THE ROLE OF COMMITMENT IN DYNAMIC CONTRACTS: EVIDENCE FROM LIFE INSURANCE
}

\author{
Igal Hendel \\ Alessandro Lizzeri \\ Working Paper 7470 \\ http://www.nber.org/papers/w7470 \\ NATIONAL BUREAU OF ECONOMIC RESEARCH \\ 1050 Massachusetts Avenue \\ Cambridge, MA 02138 \\ January 2000
}

We are very grateful to Glenn Daily. We also thank Andrew Funderburk for research assistance, and LIMRA Int. and Compulife for generously providing us access to their data. A previous version of the paper circulated under the title "Optimal Dynamic Contracts: Evidence from Life Insurance." The views expressed herein are those of the authors and not necessarily those of the National Bureau of Economic Research.

(C) 2000 by Igal Hendel and Alessandro Lizzeri. All rights reserved. Short sections of text, not to exceed two paragraphs, may be quoted without explicit permission provided that full credit, including $\mathbb{C}$ notice, is given to the source. 
The Role of Commitment in Dynamic Contracts:

Evidence from Life Insurance

Igal Hendel and Alessandro Lizzeri

NBER Working Paper No. 7470

January 2000

JEL No. L0, D4, D8

\section{ABSTRACT}

We look at the life insurance industry to study the properties of long term contracts in a world where consumers cannot commit to a contract. The main issue is how contracts are designed to deal with classification risk. We present a model that captures the main features of this industry. The data is especially suited for a test of the theory since it includes information on the entire profile of future premiums. The lack of commitment by consumers shapes contracts in the way predicted by the theory. All types of contracts involve front-loading. This generates a partial lock-in of consumers. Contracts that are more front-loaded have a lower present value of premiums over the period of coverage. This is consistent with the idea that more front-loaded contracts retain better risk pools. The estimates suggest that classification risk is almost completely insured by long term level-premium contracts.

Igal Hendel

Department of Economics

Princeton University

Princeton, NJ 08544

and NBER

igal@princeton.edu
Alessandro Lizzeri

Department of Economics

Princeton University

Princeton, NJ 08544

lizzeri@princeton.edu 


\section{Introduction}

This paper focuses on the issue of long term insurance in a world where risk types evolve over time. Health and life insurance are industries where this issue is important. In this environment, first best would involve full insurance against two sources of risk: the short term "event" risk that an accident will occur within a period, and the longer term "classification" risk, i.e., the risk that future information about the consumer's type will lead to variability in future premiums. As was pointed out by Cochrane (1995), commitment by insurance companies to the future terms of the policies is not necessarily sufficient to guarantee that classification risk can be fully insured. ${ }^{1}$ If consumers cannot commit, those who receive positive (better than average) news about their risk characteristics will switch to a competing insurance company who offers them better rates. Thus, insurance companies cannot profitably offer consumers full insurance against classification risk. This issue has important welfare and policy implications; the lack of long term insurance (or lack of renewability of contracts) is considered an important market failure in the health insurance and life insurance markets. ${ }^{2}$

A growing literature (cf. Chiappori (1999)) advocates the use of insurance data as ideal for testing the predictions of contract theory. The main focus of this literature has been on testing predictions of static moral hazard and adverse selection models. This paper also uses insurance data in an attempt to contribute to the smaller literature that studies the properties of dynamic contracts. ${ }^{3}$ An empirical investigation of contract dynamics is, in principle, a much more difficult task as the theory becomes more complex and the data requirements more demanding. We argue below that available data on life insurance contracts lends itself to a very simple test of the key aspects of the theory.

We use a unique data set on the U.S. life insurance industry. This data set includes not only information on actual life insurance contracts, but also reports for each contract

\footnotetext{
${ }^{1}$ See Cochrane (1995) for a scheme that can solve the commitment problem.

${ }^{2}$ cf. Diamond (1992), Cochrane (1995). In a 1993 Gallup poll (Piucci (1993)), 56\% of the respondents were very concerned of the possibility of losing health insurance for medical reasons. For a very recent and extensive survey of the literature and issues in life insurance, see Villeneuve (1999).

${ }^{3}$ The few papers are: Chiappori, P.A.; Salanie', B.; and Valentin, J. (1998) that test a model of wage dynamics using data from one large French firm. They find support for theories of learning with downward rigidity of wages. Murphy (1986) investigates a longitudinal sample of chief executive officers from more than 1000 firms and compares learning and incentives. His evidence is mixed. To our knowledge the only empirical work testing ideas of the theory of contract dynamics outside the labor market are Dionne and Doherty (1994) and Crocker and Moran (1998), the latter studies employee lock-in as way to increase commitment to long term insurance, lock in makes it harder for good types to leave a firm.
} 
the time profile of future premiums (including, when appropriate, how premiums vary with relevant contingencies). We exploit the differences across offered contracts to: First, test the empirical predictions of the model. Second, to study the way in which the life insurance industry copes with the lack of consumer commitment (see footnote 2). The test is extremely simple but quite informative.

The aims of the paper are: i) to develop a dynamic model that adapts existing theories to obtain testable implications; ii) to test the implications of the theory by using data on life insurance contracts; iii) to evaluate the distortions from the lack of commitment.

We present a model where insurance companies can commit to the future terms of policies but consumers cannot. ${ }^{4}$ We assume that there is perfect competition in the supply of insurance. 5 The health status of each consumer is publicly observed and evolving over time. Capital markets are imperfect and consumers are heterogeneous in the extent to which they are credit constrained. ${ }^{6}$ The main empirical predictions of the model are the following: (1) Optimal contracts involve front-loading. This creates a partial lock-in of consumers. (2) Contracts that are more front-loaded are more effective at locking in consumers, hence they keep a higher proportion of insureds in the long run, i.e., they have lower lapsation. (3) Better risk types have higher incentive to lapse since they get better terms by competing insurance companies. Thus, contracts with higher lapsation retain worse risk pools. (4) A worse risk pool translates into a higher present value of premiums for a fixed period of coverage. (5) Consumers with looser credit constraints choose contracts that are more front-loaded.

Observe that the chain of reasoning from (2) to (4) implies that contracts that are more front-loaded should keep a better risk pool, and that we should expect a negative relation between front-loading and the present value of premiums.

We exploit the variety of contracts offered in the life insurance market to test the predictions of the model; these get strong support in the data. We find that virtually every contract involves some front-loading. Observe that with imperfect capital markets front-loading is costly for consumers. Furthermore, an interesting aspect of the data is that there are large

\footnotetext{
${ }^{4}$ The model is closely related to the Harris and Holmstrom (1982) paper on wage dynamics; it departs by introducing two elements critical to the life insurance markets, namely, the within period risk of death and heterogeneity in consumers credit constraints. The relation with Harris and Holmstrom and with De Garidel (1998) will be discussed in more detail in section 2.

${ }^{5}$ We will argue later that this is a reasonable assumption in this industry. The results, however, do not depend on a literal interpretation of this assumption.

${ }^{6}$ If there are no capital market imperfections the first best can be achieved by having consumers borrow to pay all the premiums up front. Thus, capital market imperfections are essential to study the issue of commitment.
} 
differences in the present value of premiums across contracts. We find a strong and negative relation between the extent of front-loading and the present value of premiums. This confirms the relation predicted by the model. We also find that the longest term contracts come close to capturing all the gains from long term insurance despite the lack of commitment on the part of consumers. This finding is in sharp contrast with what would be expected under competition and lack of commitment (and in light of the health insurance experience), where a sequence of short term contracts leave the insured subject to reclassification risk.

We conclude the empirical analysis by presenting a more tentative, although suggestive, study of the link between the type of contract and income profile of the insured. For this part of the investigation, the data we have is not ideal. However, the predictions of the model regarding type of contract chosen by different professions and insureds at different ages are mostly reflected in the data.

We conclude by considering alternative theories that may account for the main findings and we argue that they are inconsistent with the data.

Our analysis suggests that the extent of the distortions due to dynamic information revelation in the life insurance industry are not large. The industry is reducing the reclassification risk by locking in customers. According to our numbers, some of the commonly purchased term contracts come very close to capturing all the gains from long term insurance. It should be noted however, that this achievement comes at a cost because it requires consumers to pay more money up front than would be optimal from the point of view of intertemporal consumption smoothing. It is worth noting that the industry achieved this partial solution to the problem of classification risk without need of regulation (e.g., no imposition of guaranteed renewability).

Why Life Insurance? Beside the fact that the life insurance market is interesting in its own right, several factors make it an ideal environment for studying the issue of commitment. ${ }^{7}$

(1) In this market learning about the characteristics of individuals is a crucial issue; it is known that the premiums charged to consumers depend on their state of health. Furthermore, our empirical investigation is unlikely to be seriously contaminated by other phenomena. First, adverse selection is unlikely to be a major consideration. Cawley and Philipson (1998) found no evidence of adverse selection in life insurance. ${ }^{8}$ This can be explained by

\footnotetext{
${ }^{7}$ Concerning the importance of the market, Cawley and Philipson (1998) report that premiums make up $3.6 \%$ of GDP in the U.S. and $90 \%$ of families with 2 adults have life insurance of some kind.

${ }^{8}$ They test for adverse selection by looking at the relation between the face amount and the unit price.
} 
the fact that buyers have to pass a medical examination and answer a detailed questionnaire. Misrepresentation or concealment of material information would render the policy void. Furthermore, insurance companies have an information clearing system. ${ }^{9}{ }^{10}$ Moral hazard is unlikely to be a quantitatively important issue; it is known that the insured population outlives the uninsured, hence, if moral hazard is present it is dominated by the medical screening.

(2) Data on contracts is available. A contract pre-specifies all future renewal prices and conditions for renewal. To our knowledge no previous work on the dynamics of contracts has used direct contract information. Life insurance also has the advantage that the terms of the contract are simple and clearly stated. Labor contracts, in contrast, are plagued by unobservables (e.g. performance related) and by the presence of implicit agreements which are hard to account for explicitly in empirical work. In contrast with other types of insurance, the potential for misreporting or mismeasuring the magnitude of an accident is lower in the case of life insurance. ${ }^{11}$

(3) Life insurance contracts are offered in several varieties, involving different time profiles of premiums. This variety is essential to analyze the effects of commitment and renegotiation. We use this variety to test the implications of the model.

(4) Finally, understanding and quantifying the inefficiency from the lack of bilateral commitment in life insurance will contribute to the policy debate over health insurance. Lack of renewability and the absence of insurance of classification risk are some of the concerns raised about health insurance (e.g. in Clinton's reform proposal, new state regulation during the $90 \mathrm{~s})$. However, the health care market suffers from a variety of other problems. Isolating the problems due to the lack of bilateral commitment should be useful for understanding the source of inefficiency in health insurance (see Concluding Section).

If adverse selection was a serious issue one would expect a positive relation; this is not present in the data.

${ }^{9}$ In practice there is an informational asymmetry, in the sense that the insurer learns the type of the insured only if the latter shows up for a medical examination. What matters for our purposes is that this asymmetry disappears (or becomes quantitatively unimportant) at the moment of underwriting (or renewing the contract). In the model, for simplicity, we assume the information is symmetric. The assumption is inconsequential since the insured cannot hide his type in case he wants to transact.

${ }^{10}$ Our assumption of no adverse selection would not be valid for annuities: there is evidence that annuity markets (which seem to be under developed) suffer from adverse selection (Brugiavini (1990) and Friedman and Warshawski (1990)). A key distinction is that purchases of annuity do not require medical exams. The reason may be that this would give consumers the incentive to hide good information about their health, which is arguably much easier than hiding bad information (think about a non smoker showing up to the medical exam smoking a cigarette and coughing repeatedly).

${ }^{11}$ In auto insurance for example, policy-holders have the incentive not to report minor claims. 


\section{Theory}

\subsection{Model}

There are three sets of agents in the model: Insurance companies, consumers and dependents of the consumers. Consumers wish to insure the stream of income for their dependents. Dependents will not play an active role in the model; they only affect the solution indirectly through the utility that consumers attach to consumption by their dependents. We assume that there is perfect competition between insurance companies. ${ }^{12}$

There are two periods. In period 1 all agents have identical death probabilities $p .{ }^{13}$ In period 1 there are 3 stages: in stage 1 insurance companies offer contracts to consumers. At stage 2 consumers choose a contract. At stage 3 uncertainty about death is resolved and all living consumers consume. In period 2 there are 4 stages. In stage 0 a health status $i$ is realized. Each health status occurs with probability $q_{i}$. A consumer with health status $i$ dies with probability $p_{i}$ in period 2 . Without loss of generality, we order the health status so that $p_{1}<p_{2} \ldots<p_{N}$. We assume that $p_{1} \geq p$, i.e., health worsens over time. In stage 1 all insurance companies observe the health status of all individuals and offer contracts to agents. In stage 2 consumers choose a contract. In stage 3 uncertainty about death is resolved and all living consumers consume.

Consumers have expected utility preferences that are time additive. When alive a consumer gets utility $u(c)$ from consuming an amount $c$ in a given period. All consumers expect a utility $v(c)$ if the dependents consume $c$ in a given period when he is dead. The functions $u$ and $v$ are both assumed to be strictly concave and twice differentiable. If a consumer is alive he receives a first period income of $y-g$ and a second period income of $y+g$, with $g \geq 0$. If he is dead the family receives no income except for the face amount of the insurance $F$. There are no credit markets. Consumers have the same preferences and the same permanent income but different consumers have different income growth, as represented by the parameter $g$. The role of this parameter is to allow a comparison across individuals who have different needs for consumption smoothing and hence are different in the extent to which

\footnotetext{
${ }^{12}$ While there are search costs, we believe that perfect competition is a good approximation for term life insurance: there are 1500 competing companies and term insurance is increasingly viewed as a commodity (Record (1997)). There is a regulatory presence but regulation mainly pertains to financial solvency, not pricing. As Black and Skipper (1994) put it: "Life insurance rates for individual insurance are regulated only in a most indirect sense. It is felt that competition is an adequate regulator over any tendencies toward rate excessiveness".

${ }^{13}$ We can think of $p$ as representing a specific risk category in period 1 . Our model can be readily extended to treat several such categories.
} 
credit constraints affect their decisions. ${ }^{14}$

A period 1 contract is a first period premium $Q_{1}$ and a face amount $F_{1}$, and a vector of premiums and face amounts $\left(Q_{2}^{1}, \ldots, Q_{2}^{N}\right),\left(F_{2}^{1}, \ldots, F_{2}^{N}\right)$ indexed by the second period health status of an individual. The second period premiums will only be paid if the consumer does not change contract. A period 2 contract is a premium and face amount $\left(Q_{2}^{i}, F_{2}^{i}\right)$ indexed by the second period health status of an individual.

\subsection{Benchmarks}

Full Commitment If both parties can commit to a long term contract, then risk neutral firms fully insure risk averse consumers, equating marginal utilities across periods and states. Competition drives profits to zero. The allocation is Pareto efficient.

No Commitment If neither party is able to commit then the equilibrium allocation involves short term contracts; in each period agents purchase actuarially fair insurance given their type. Short term risk is fully insured, but classification risk is completely uninsured.

\subsection{One-sided Commitment}

From now on we shall assume that insurance companies can commit to future actions whereas consumers cannot. Given the health status, in period 2 a consumer chooses between staying: with the contract he chose in period 1 and the set of contracts on offer in period 2. Thus, the set of feasible contracts is the set of unilateral contracts, i.e., those contracts that terminate the moment the buyer stops paying the premiums; there are no cash flows upon termination. ${ }^{15}$

The time line in figure 1 summarizes the model.

It is clear that the competitive equilibrium is characterized by the solution that maximizes the utility of consumers subject to insurance companies breaking even. The equilibrium is thus characterized by the solution of the following maximization problem:

\footnotetext{
${ }^{14}$ Absence of credit markets is a too extreme assumption, we only need some source of financial imperfection that makes borrowing differentially costly. So that consumers pay different interest rates for loans. We believe that the conclusions would be similar in that case.

${ }^{15}$ This is exactly the kind of life insurance contract that is offered in the U.S. market. As we will see later, insurance companies do commit to long term contracts. As to consumers, the contracts available in the life insurance market do not impose penalties on consumers who drop out of the contract. It would probably be impossible to enforce such penalties. For more on institutional features of life insurance see Mc Gill (1967) or Daily (1989).
} 
Period 1

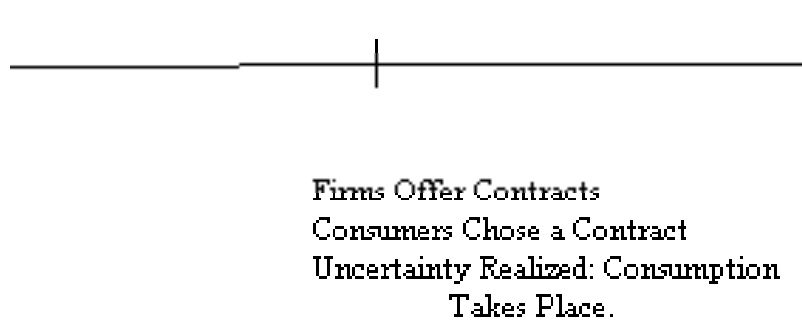

Period 2

Uncertainty About Health State is Realized

Fims Offer Contracts: Contingent on State i

Consumers Chose a Contract or Stick to Their Old Ones

Uncertainty Realized: Consumption Takes Place.

Figure 1:

$$
\begin{aligned}
& \underset{Q_{1}, F_{1},\left(Q_{2}^{1}, \ldots, Q_{2}^{N}\right),\left(F_{2}^{1}, \ldots, F_{2}^{N}\right)}{\operatorname{Max}} p v\left(F_{1}\right)+(1-p) u\left(y_{1}-g-Q_{1}\right)+ \\
& (1-p) \sum_{i=1}^{N} q_{i}\left[p_{i} v\left(F_{2}^{i}\right)+\left(1-p_{i}\right) u\left(y_{2}+g-Q_{2}^{i}\right)\right]
\end{aligned}
$$

Subject to

$$
\begin{gathered}
(1-p) Q_{1}-p F_{1}+(1-p) \sum_{i=1}^{N} q_{i}\left[\left(1-p_{i}\right) Q_{2}^{i}-p_{i} F_{2}^{i}\right]=0 \\
\left(1-p_{i}\right) Q_{2}^{i}-p_{i} F_{2}^{i} \leq 0 \text { for } i=1, \ldots N
\end{gathered}
$$

Constraint (3) says that each contract that is chosen by consumers in period 1 must in equilibrium yield zero expected profits to insurance companies over the two periods. The set of constraints in (4) says that contracts in the second period contracts cannot make positive profits in any state. The reason is that otherwise some insurance company would offer an actuarially fair contract (in that state of the second period) that makes consumers better off. Since consumers do not commit, a contract that makes positive profits in some state in the second period is not sustainable.

We need to separate between event risk and classification risk. Event risk is the risk of death in the following period. Classification risk is the risk of paying different premiums in different states. We need to define what full insurance is when consumers have state dependent utility. 
Definition 1 We say that a consumer gets full event insurance in state $i$ of date 2 if

$$
v^{\prime}\left(F_{2}^{i}\right)=u^{\prime}\left(y_{2}+g-Q_{2}^{i}\right)
$$

Analogously, we say that a consumer gets full event insurance at date 1 if

$$
v^{\prime}\left(F_{1}\right)=u^{\prime}\left(y_{1}-g-Q_{1}\right)
$$

We call $Q_{2}^{i}(F I)$ the fair premium for full insurance in state $i$

Proposition 1 In the equilibrium set of contracts all consumers get full event insurance in period 1 and in all states of period 2 .

See the appendix for the proof. The intuition for this result is that, under competition event insurance is offered at a fair rate, hence, consumers are free to transfer resources between the "alive" state and the "dead" state. Hence, they will always choose to fully insure event risk.

The next is the main theoretical result. It provides a characterization of the equilibrium set of contracts.

Proposition 2 In the equilibrium set of contracts:

(i) There is a $\bar{g}$, such that, if $g<\bar{g}$ there is an s such that $1 \leq s<N, Q_{2}^{i}=Q_{2}^{i}(F I)$ for $i=1, \ldots, s-1$, and $Q_{2}^{i}=Q_{2}^{s}$ for $i=s, \ldots, N$ and $Q_{2}^{i}<Q_{2}^{i}(F I)$ for $i=s+1, \ldots, N$.

(ii) The first period premium is larger than actuarially fair.

(iii) There is a negative relation between income growth $g$ and the first period premium $Q_{1}$, and there is a positive relation between $g$ and $s$.

See the appendix for the Proof. The content of Proposition 2 is summarized in figure 2.

The intuition for Proposition 2 is the following. Part (i) is saying that there is a health state $s$ such that for all health states where the consumer is at least as healthy as in $s$, the premiums are actuarially fair. For all health states where a consumer is in worse health than in state $s$ the premiums are lower than actuarially fair, and equal to the premium in state $s$. We can think of $s$ as separating between "good" and "bad" states in the second period. Because of the lack of commitment by consumers, it is not possible to transfer resources across states in the second period. However, by front-loading, it is possible to transfer resources between the first period and the bad states in the second period. This is not costless given the absence of capital markets. However, it is worth doing if the consumer is relatively badly off in the bad states of the second period relative the first period. This 


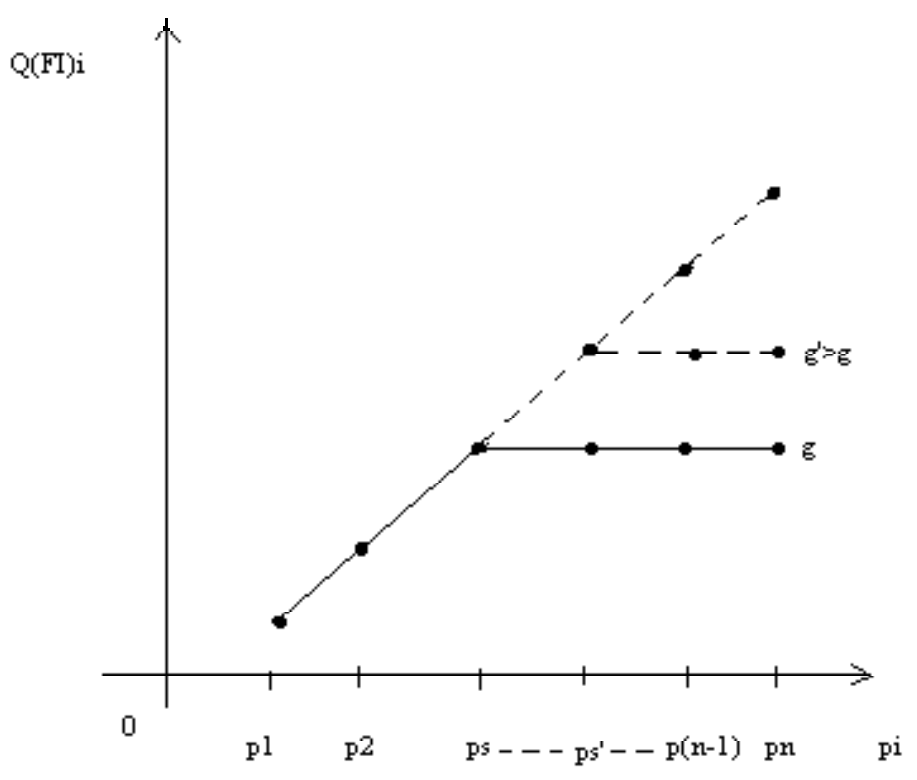

Figure 2:

happens if the highest death probabilities are relatively high and if income growth is not too extreme. The premiums in the bad states are all the same because otherwise risk can be smoothed further across the bad states.

Part (iii) says that there is going to be less front-loading for consumers with higher income growth, given a level of permanent income. This is because, when credit markets are imperfect, income growth implies an intertemporal distortion in consumption. Since this distortion is larger the larger $g$, and because front-loading the premiums exacerbates this distortion, consumers with larger $g$ are less willing to front-load the premiums. ${ }^{16}$

\subsection{Empirical Implications}

An immediate implication of Proposition 2 is that we should observe front-loading and pooling of risk categories. We shall verify this in the empirical discussion.

Proposition 2 has implications on non-state contingent contracts as well. To see this notice that every optimal contract $\left(Q_{1}, F_{1}\right),\left(Q_{2}^{1}, \ldots, Q_{2}^{N}\right),\left(F_{2}^{1}, \ldots, F_{2}^{N}\right)$ can be transformed into a non-contingent contract $\left(Q_{1}, F_{1}\right),\left(Q_{2}^{s}, F_{2}^{s}\right)$ which is allocationally equivalent. The contracts are identical in the first period and in states $i=s, . ., N$. In states $i=1, . ., s-1$

\footnotetext{
${ }^{16}$ Notice that for a very large $g$ there may be no front-loading at all, i.e., $s=N$. That is why the statement of the proposition qualifies for a $g$ not too large.
} 
the consumer drops out of the non-contingent contract and gets the spot (fair) rate, which is equal to the premium charged in the original contract. Thus, the consumer is indifferent between the contingent and the non-contingent contract; the insurer is also indifferent since in states 1 to $s$ premiums are actuarially fair (i.e., no loss of profits from losing the customer in those states).

Non-contingent contracts are common in the life insurance market. Thus, it is important for our empirical analysis to describe their properties.

Proposition 3 Consider two contracts offered in the first period that are not contingent on the health state in period 2. In equilibrium, the contract with the higher first period premium will have a pool of consumers in better health and a lower present value of premiums. The contract with the higher first period premium is chosen by consumers with lower income growth.

Proof: Clearly, the contract with the higher first period premium must have a lower second period premium since otherwise no consumer would choose it. Thus, in the second period this contract will retain a healthier pool of consumers. This implies that the average cost of this contract (payments to dependents of deceased policy holders) is lower. Under competition this implies that the present value of the premiums must also be lower.

The fact that the contract with the higher first period premium is chosen by consumers with lower income growth is obvious.

\section{Remarks:}

- We can also apply Proposition 3 to state contingent contracts. To do this recall from the discussion above that we can take out part one of the contract (the set of states where the constraints (4) are binding) and only look at the rest of the contract. The predictions of Proposition 3 hold for comparisons among these "amputated" contracts. ${ }^{17}$

- There are alternative sources of heterogeneity that may explain why different consumers may prefer different extents of front-loading. Examples are uncertain needs for life insurance or different interest rates for borrowing. However, the predictions of Proposition 3 are robust as long as consumers incentives to lapse are related to health.

\footnotetext{
17 Notice that a higher present value conditional on not requalifying does not mean that more front-loaded contracts are ex-ante cheaper, they should be equally costly in expectation. More front-loaded contracts do leave the insured subject to lower risk of reclassification.
} 
Related Models Our model is related to Harris and Holmstrom (1982) who study wage dynamics in a model where firms and workers learn the ability of the workers over time. Firms can commit to sequences of wage offers contingent on any public information but workers cannot commit to stay in the firm. Since workers are risk averse, the first best allocation involves constant wages over time and information states. However, the equilibrium involves wages that are rigid downward and expected to increase over time as firms match offers made to those workers who are revealed to be of high ability. Furthermore, workers receive wages below their expected ability in the first few periods. De Garidel (1998) also adapts Harris and Holmstrom to an insurance setting. His main focus is the case where there is asymmetric information about the type of the driver. He discusses the desirability of requiring insurance companies to share their information about the drivers' accident records.

Cochrane (1995) shows the efficient allocation can be achieved using a sequence of short term contracts with severance payments that cover future changes in premiums. This kind of scheme is not observed in the life insurance market. As discussed in the beginning of section 2.3, we focus on the type of contracts that are observed in the market.

\section{The Contracts and the Data}

The Contracts The life insurance market is segmented in Term and Cash Value. Term contracts offer pure protection: they pay a fixed sum upon death of the insured should death occur within the period of coverage. Cash value policies in contrast offer a combination of insurance and savings; policy-holders deposit over time with the possibility of withdrawing later on. We focus our analysis on the market for Term insurance for two reasons. First, term is simpler since it involves pure insurance. Second, we do not have data on cash value.

Term contracts differ in length, ranging from yearly to 30 years. ${ }^{18}$ Contracts are renewable, so the length of the contract does not per se dictate the period of coverage. Premiums are fixed for the length of the contract, but increase with each renewal. Thus, shorter term contracts face more frequent increases for a given period of coverage. Renewability is guaranteed without medical examination at a pre-specified price (not necessarily guaranteed). It should be noted that: First, since no medical examination is needed to renew, price changes are not insured specific. Second, insurers rarely change the pre-announced prices. Hence, although not legally binding, pre-announced prices represent the relevant future terms of the

\footnotetext{
${ }^{18}$ Term contracts have gained popularity since 1945 . They represented only $6 \%$ of all ordinary life insurance in 1954 (Life Insurance Fact Book, 1993), but over 37\% in 1997 according to LIMRA Buyer's Study.
} 
contract. $^{19}$

\begin{tabular}{|c|c|c|c|c|c|c|c|c|c|c|c|}
\hline \multicolumn{11}{|c|}{ Table 1} & \\
\hline Age & ART & LT10 & \multicolumn{8}{|c|}{ S\&U ART } & \\
\hline & & & \multicolumn{6}{|c|}{ Policy Year } & & & \\
\hline & & & 1 & 2 & 3 & & 10 & 11 & & 19 & 20 \\
\hline 35 & 614 & 714 & 670 & 790 & 1020 & $\ldots$ & 3290 & 3530 & $\ldots$ & 7440 & 8280 \\
\hline 36 & 634 & 714 & 680 & 830 & 1060 & $\ldots$ & 3550 & 3820 & $\ldots$ & 8200 & 9130 \\
\hline 37 & 664 & 714 & 690 & 870 & 1130 & $\ldots$ & 3830 & 4120 & $\ldots$ & 9040 & 10060 \\
\hline$\vdots$ & $\vdots$ & $\vdots$ & $\vdots$ & $\vdots$ & $\vdots$ & & $\vdots$ & $\vdots$ & & $\vdots$ & $\vdots$ \\
\hline 44 & 1184 & 714 & 890 & 1270 & 1650 & $\ldots$ & 6920 & 7570 & $\ldots$ & 17830 & 20000 \\
\hline 45 & 1284 & 1544 & 940 & 1350 & 1750 & $\ldots$ & 7560 & 8350 & $\ldots$ & 19800 & 22210 \\
\hline 46 & 1394 & 1544 & 1040 & 1460 & 1880 & $\ldots$ & 8320 & 9200 & $\ldots$ & 21990 & 24630 \\
\hline$\vdots$ & $\vdots$ & $\vdots$ & $\vdots$ & $\vdots$ & $\vdots$ & & $\vdots$ & $\vdots$ & & $\vdots$ & $\vdots$ \\
\hline 53 & 2344 & 1544 & 1810 & 2420 & 3200 & $\ldots$ & 16390 & 18290 & $\ldots$ & 44220 & 49700 \\
\hline 54 & 2544 & 1544 & 2030 & 2650 & 3440 & $\ldots$ & 18190 & 20310 & $\ldots$ & 49210 & 55400 \\
\hline
\end{tabular}

The first column of Table 1 illustrates an Annual Renewable Term (ART) contract. This is an aggregate ART, where premiums vary exclusively by attained age. Column 2 illustrates a 10-year Term contract. The main distinction is the profile of premiums.

In the mid-1970s insurers started to market a new variety of ART, the Select and Ultimate (S\&U) ART. ${ }^{20}$ These contracts offer state contingent prices; premiums vary by issue age and duration since underwriting. The logic is to reflect the lower mortality rates of those just screened by the medical examination. ${ }^{21}$ Insureds can avoid the increased premiums by requalifying for the select period, provided they are still in good health. ${ }^{22}$ The right side of Table 1 illustrates a S\&U ART. Payments are expressed as a matrix since they do not only

\footnotetext{
${ }^{19}$ According to Consumer Reports (July 1993), among the 67 companies surveyed, only one increased term premiums between 1989 and 1993.

${ }^{20}$ Since their introduction S\&U contracts have largely displaced aggregate ones. In our data set 81 out of the 113 ART are S\&U ones.

21 "There is a measurable disparity for at least fifteen years; but for practical purposes, it is generally assumed that the effect of selection "wears-off" after approximately five years." (McGill (1967))

22 "The insured may only have to answer three of four questions about his health in the last year ... The reversion process can be repeated as long as the insured remains a standard risk and below a specified age (typically 70)." Dukes and MacDonald (1980).
} 
depend on age, but on years since underwriting (captured by Policy Year). This additional state variable fits with the hypothesis that information about death probabilities is revealed over time. Time elapsed since the last medical provides information about the insured. For instance, at age 36 the insured would pay $790 \$$ for renewing his insurance, while had he requalified he would have paid only $680 \$$. The incentive to requalify increases in age. While the saving is moderate for a 36 year old, at 54 not requalifying means a $25 \%$ premium increase, the insured would pay $2420 \$$ instead of $2030 \$$.

The big difference in premiums in the different scenarios of a S\&U ART is clearly suggestive of the fact that learning about the health status of an individual is an important phenomenon, and that consumers my be left to suffer significant classification risk.

The Data Most of the data we use in this section is from the Compulife Quotation System (July 1997). Compulife is an information system used by insurance agents; it contains quotes by the main U.S. Life insurers (240 firms). Premiums are reported by consumer characteristics such as age, smoking status, gender, etc. It is a very accurate source of pricing data, as it is the actual source of quotes that insurance agents offer to their clients. ${ }^{23}$ Its unique feature, for the purpose of testing the predictions of the model, is that it reports the whole profile of future premiums faced by a buyer at the moment of underwriting. Thus, we observe the entire contract profile, not just the starting premium.

We included the top 43 insurers in the U.S. ${ }^{24}$

\section{Testing the Implications of the Model}

The presence of several contract profiles is consistent with the model of Section 2 but not necessarily evidence in favor of the theoretical link between price profiles and degrees of commitment explain the observed contracts. We now look at the dynamics of prices and lapsation for the various policies to test the specific implication of the model. The model predicts: 1. Optimal contracts involve front-loading (Proposition 2). 2. Contracts with

\footnotetext{
${ }^{23}$ Agents are forbidden from offering discounts by the anti-rebating statutes, hence the premiums we report reflect actual transaction prices.

${ }^{24}$ These are the firms in categories XV, XIV and XIII of A.M. Best ratings. Ratings reflect financial strength according to A. M. Best. We chose these categories, the top rated, since solvency is highly related to the size of the firm. Twenty-one of the firms in our sample (for which we were able to find sales figures) held $46.8 \%$ of the 2,937 billion dollars of in force face amount of term insurance in 1996 (Best's Review July 1996). We do not have sales information for the rest of the companies in our sample, but clearly a large share of the market is covered.
} 
higher front-loading keep higher proportions of insureds in the long run, i.e., lower lapsation (Proposition 3). 3. Since better risk types have higher incentive to lapse any given contract, higher lapsation implies worse pools (Propositions 3). 4. A worse pool translates into higher present value of premiums for a fixed period of coverage (Proposition 3).

\subsection{Contract Profiles}

The odd columns of Table 2 show the yearly premiums paid by a 40 year old purchasing coverage for half a million dollars for 20 years under three different contracts: aggregate ART (columns 1), 20 year term (column 3), and S\&U ART (columns 5 and 7) under two alternative scenarios: in column 5 the consumer never requalifies, in column 7 he always requalifies. ${ }^{25}$ Observe the substantial difference in payment profiles. By definition, premiums in the 20 year term contract are constant in nominal terms. Due to discounting and aging, the term contract presents a high degree of front-loading; the payments in the first few years are much higher than actuarially fair. The first payment in the 20 year policy is more than $50 \%$ higher than in the yearly select contract; this is a lower bound on the magnitude of front-loading.

The initial over-payment creates the consumer lock-in. When the insured reaches age 50, he cannot be lured by a S\&U ART, since the remaining premiums are lower in his current long term contract than those he would pay in a S\&U ART (even if he were to keep requalifying as a select customer).

Note also that the first year payment in an aggregate ART is almost $30 \%$ higher than in a select contract despite the fact that both are yearly contracts. We argue that this reflects the fact that in an aggregate contract the insurance company is offering a costly renewal option to the consumer since it is going to be exercised only in the event the consumer is not as healthy as the average pool. This option to renew is available under the select contract as well but it is not as costly since the company is going to charge different prices to the consumers depending on their health status. The aggregate contract offers more insurance of classification risk, at the cost of higher initial payments.

\footnotetext{
${ }^{25}$ The numbers are averages over all companies that offer each contract.
} 


\begin{tabular}{|c|c|c|c|c|c|c|c|}
\hline \multicolumn{10}{|c|}{ Table: 2} \\
\hline & Agg ART & \multicolumn{1}{|c|}{ LT20 } & \multicolumn{1}{c|}{ SU ART: NoReq } & SU: Req \\
\hline & 1 & 2 & 3 & 4 & 5 & 6 & 7 \\
\hline 40 & 593 & 100 & 719 & 100 & 454 & 100 & 454 \\
\hline 42 & 685 & 60 & 719 & 52 & 671 & 74 & 489 \\
\hline 44 & 801 & 51 & 719 & 38 & 877 & 76 & 530 \\
\hline 46 & 950 & 64 & 719 & 29 & 1,148 & 72 & 598 \\
\hline 48 & 1,129 & 40 & 719 & 21 & 1,478 & 69 & 689 \\
\hline 50 & 1,327 & 39 & 719 & 17 & 2,298 & 87 & 800 \\
\hline 52 & 1,530 & 36 & 719 & 14 & 2,838 & 86 & 927 \\
\hline 54 & 1,776 & 34 & 719 & 10 & 3,514 & 81 & 1,080 \\
\hline 56 & 2,118 & 28 & 719 & 8 & 4,229 & 73 & 1,271 \\
\hline 58 & 2,599 & 28 & 719 & 7 & 5,134 & 72 & 1,520 \\
\hline \multicolumn{10}{|c|}{ Odd-numbered columns present average premium in } \\
the sample paid at different ages by a consumer who buys \\
insurance at 40. Even columns present the premium over \\
\multicolumn{18}{|c|}{ death probability ratios. } \\
\hline
\end{tabular}

\subsection{Front-loading}

As argued above, level premium contracts clearly involve front-loading. We now argue that even ARTs are front-loaded. To check this, in the even columns of Table 2 we report the ratio of yearly premium over the probability of death; the ratio was normalized to equal 100 at age $40 .{ }^{26}$ This ratio should be constant absent front-loading. In contrast, the ratio declines over time. For example, for a 40 year old and an aggregate ART policy the ratio halves within 4 years, and it keeps declining to well below a third of its initial level. Hence, contracts do not break-even period by period. This is in line with our model's predictions, and in contrast with the predictions of a model of no commitment.

More surprisingly, even S\&U ARTs, which are state contingent contracts, an obvious candidate for involving no long term components, involve some degree of front-loading. Column

\footnotetext{
${ }^{26}$ The death probabilities that we used for table 2 are the ones for the general population. This understates the extent of front-loading for ARTs since these contracts only retain those consumers who are in a worse state of health. One caveat concerns the trend of decreased mortality. The mortality tables that we have refer to past populations whereas the contracts presumably reflect a decline in mortality. However, the declines in the ratios that we observe in table 2 are too pronounced to be explained by a general improvement in mortality.
} 
6 confirms this. If premiums reflected the worst possible draws the ratio should increase over time since the denominator reflects the entire population and the numerator the worsening pool in the contract. In contrast, the ratio mildly declines. Furthermore, the difference in premiums between requalifying and not requalifying (columns 5 vs. 7) seems too small to suggest the complete ratcheting of good health types that would be predicted by short term contracts. $^{27}$

Another piece of evidence that ARTs involve front-loading, is that renewability options are costly. Some contracts offer longer periods of guaranteed renewability than others. If these contracts broke even period by period, then the option of renewing a contract an extra year would be costless to the insurer and under competition would be offered for free. In contrast, the option to renew a contract is priced. We compared an ART renewable for 10 years (Term 10 by NW Mutual) with another renewable to age of 70 (Term 70 by NW Mutual). The option to renew after 10 years makes the present value of the cost of the 10 years of insurance (under the second contract) $10 \%$ higher for a 35 year old individual, while $35 \%$ more expensive for a 50 year old. Hence, the renewability option is: first, priced, and second, priced higher when more costly to provide. If we look over time, the first premium paid by the 50 year old is only $15 \%$ higher under the longer contract, but $48 \%$ more expensive in the last renewable period (at age 59). This is consistent with the idea that a lot more information about health status is revealed later on in life.

In sum, all the available contracts involve front-loading like the optimal contracts in Section 2 (Proposition 2) and in sharp contrast with what would be expected in an environment with no commitment where only short term contracts would be observed.

\subsection{The Negative Relation Between Front-loading and the Present Value of Premiums}

The previous subsection showed that contracts differ in the extent of front-loading. We now show that these contracts also differ a lot in the present value of premiums. Moreover, we show that there is a systematic relation between present values and premium profiles along the lines of Proposition 3.

An eyeball comparison of existing contracts. Table 3 shows the present value of 20 years of coverage (the cost to a consumer of holding the policy for that long) starting at

\footnotetext{
${ }^{27}$ Complete ratcheting would only leave in the pool the worst risks, e.g., terminally ill patients.
} 
different ages. ${ }^{28}$ We use an $8 \%$ interest rate in computing present values. ${ }^{29}$ Comparing the first and last columns it is immediate to see that a 20 year term contract, which is more front-loaded, is cheaper than aggregate ARTs the S\&U ARTs under the assumption of no requalification. Moreover, aggregate contracts which are steeper than level ones but flatter than $\mathrm{S} \& \mathrm{U}$ fall in between their present values. This confirms the relation between the pool of types and front-loading predicted in Proposition 3.

\begin{tabular}{|r|c|c|c|c|c|c|}
\hline \multicolumn{7}{|c|}{ Table: 3} \\
\hline & ART & S\&U ART & LT10 & LT10 & LT20 \\
\hline & Agg & NoReq & Req & NoReq & Req & \\
\hline 30 & 6,167 & 9,820 & 4,716 & 10,502 & 4,653 & 5,093 \\
\hline 35 & 8,281 & 12,548 & 5,729 & 14,160 & 5,622 & 5,579 \\
\hline 40 & 12,186 & 18,558 & 7,697 & 21,377 & 7,935 & 7,620 \\
\hline 45 & 19,000 & 28,791 & 11,268 & 33,603 & 11,464 & 11,614 \\
\hline 50 & 31,062 & 45,464 & 17,917 & 54,186 & 17,385 & 17,849 \\
Present value of 20 years of coverage starting at the \\
specified ages, for different contracts, using r=8\%. \\
\hline
\end{tabular}

Moreover, the percentage gains from commitment increase in age. Savings are only $20 \%$ for a 30 year old, but a 50 year old gains almost $70 \%$. These numbers are consistent with the theory, since the learning about health state increases in age, most gains from pooling are likely to occur at later ages.

A striking feature of the numbers presented in Table 3 is how close the 20 year contract comes to the requalifying S\&U ART and the requalifying 10 year contract. The latter are over-optimistic benchmarks to evaluate the cost of insuring the whole pool, since it is based on a sequence of good draws rather then on the whole pool. This leads us to conclude that most of the attainable gains from commitment are achieved by long term level-premium contracts.

Figures 3 and 4 present graphically similar numbers to those in Table 3 . Figure 3 presents an LT20 compared to non-requalifying contracts, while Figure 4 compares LT20 to requalifying contracts. It confirm the relation between front-loading and risk pools. Aggregate contracts fall between requalifying and non-requalifying contracts, while LT20 costs are as

\footnotetext{
${ }^{28}$ The numbers are averages over all companies that offer each specific contract.

${ }^{29}$ We purposely chose a high interest rate for two reasons: First, to account for time preference and for the probability of surviving to a specific date. Second, to be on the safe side, since, as will become clear, results are reinforced if the interest rate is lower. We experimented with other interest rates and qualitative results are unchanged.
} 


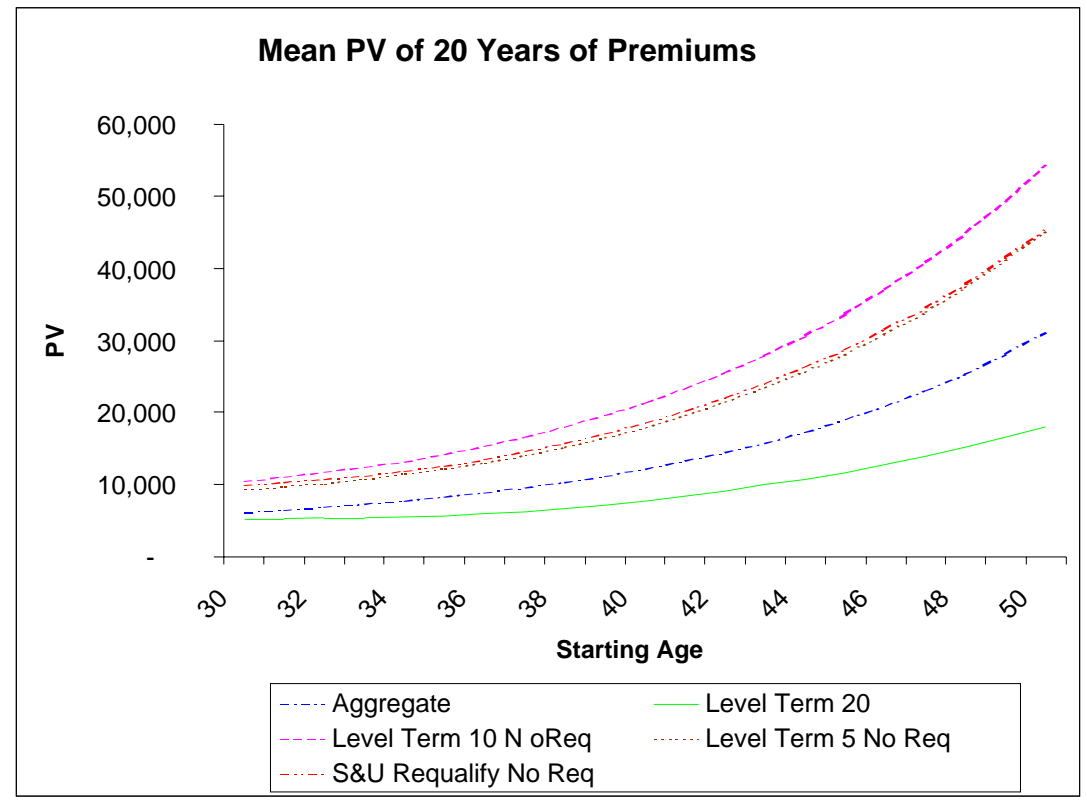

Figure 3:

low as requalifying ones.

A Systematic Comparison of Contracts. We now look more systematically at the cost differences across contract profiles. Table 4 presents regressions of the log of the present value of 20 years of coverage on age, contract dummies, contract dummies interacted with age and other policy characteristics. These policy characteristics include: for how many years the policy is renewable, for how many years the policy is convertible to other types of insurance (like whole life), and other special features such as whether the policy is offered to specific professions. The unit of observation is a policy/age. For every policy we compute the present value of 20 years of coverage starting at 30 through 50 years old. We omit the ART S\&U requalify dummy, hence all the dummies will be measuring cost differentials relative to individuals lucky enough to requalify in their ARTs every year. 


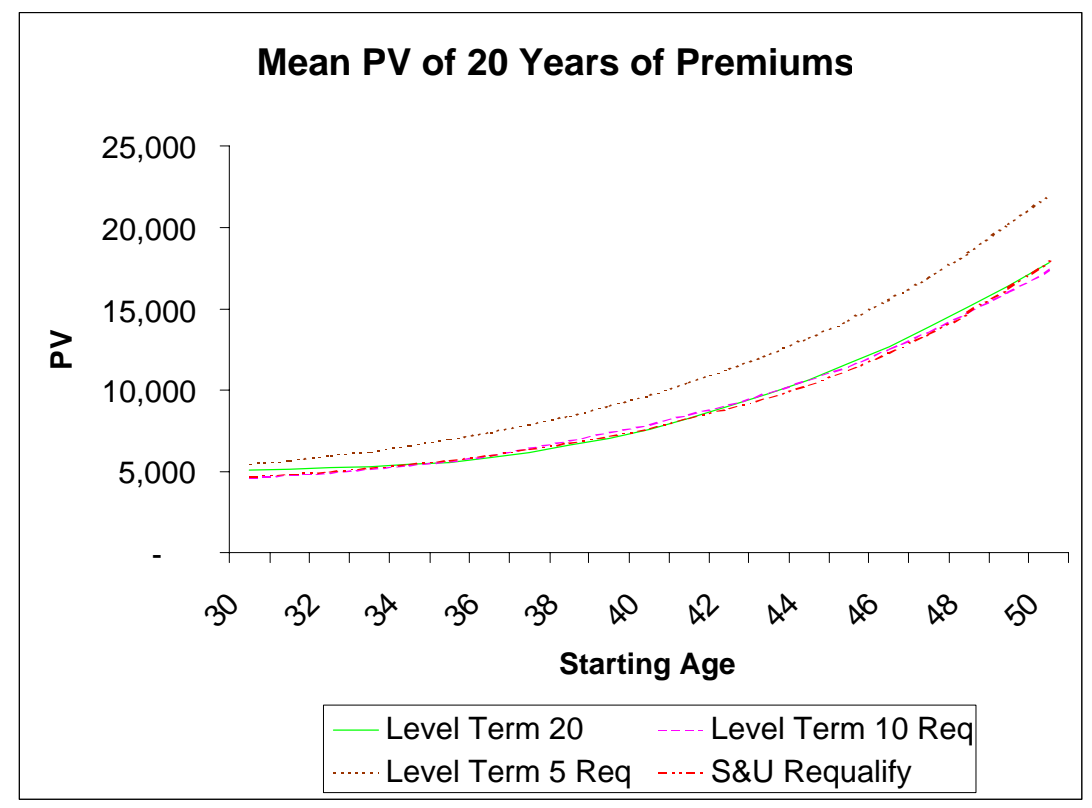

Figure 4:

\begin{tabular}{|l|c|c|c|c|}
\hline \multicolumn{5}{|c|}{ Table 4} \\
\hline & \multicolumn{2}{|c|}{$\log (\mathrm{PV})$} & \multicolumn{2}{c|}{$\log (\mathrm{PV})$} \\
\hline \hline Const (ReqSU) & 8.01 & 136.0 & 8.79 & 50.3 \\
\hline \hline LT20 & 0.06 & 1.67 & 0.03 & 0.40 \\
\hline LT10 Req & 0.01 & 0.32 & 0.05 & 0.70 \\
\hline LT5 Req & 0.18 & 4.65 & 0.22 & 2.36 \\
\hline AggART & 0.34 & 8.11 & 0.50 & 4.22 \\
\hline LT10 NorReq & 0.77 & 14.88 & 0.88 & 6.62 \\
\hline LT5 NorReq & 0.51 & 11.02 & 0.63 & 5.66 \\
\hline ART SU Noreq & 0.75 & 22.16 & 0.89 & 11.34 \\
\hline \hline Age & 0.07 & 30.35 & - & - \\
\hline Age*LT20 & -.001 & -0.32 & - & - \\
\hline Age*LT10 Req & .001 & 0.52 & - & - \\
\hline Age*LT5 Req & .001 & 0.45 & - & - \\
\hline Age*AggART & 0.013 & 3.80 & - & - \\
\hline Age*LT10 NRq & 0.012 & 2.46 & - & - \\
\hline Age*LT5 NReq & 0.012 & 3.00 & - & - \\
\hline Age*NorReqSU & 0.012 & 4.21 & - & - \\
\hline \hline Renewavab & 0.004 & 4.47 & $.00{ }^{*}{ }^{*}$ & 0.96 \\
\hline Convertib & -.002 & -3.26 & -.0002 & -0.70 \\
\hline
\end{tabular}


The results confirm the numbers presented in the previous tables. The first set of 7 coefficients are those on contract dummies, the next 8 coefficients are those on age and interactions between contract and age. The former represent the differences across contracts for the base age (30 year old buyers), while the latter capture the slope of the cost of different contracts as a function of age.

The most front-loaded contract, the 20-year level term, is one of the cheapest. It is interesting to notice how close this 20 -year contract is to the 5 or 10 -year contracts under the requalifying assumption. It means that even the lucky buyers of a 10 year contract do not do much better than by locking into a 20 year contract, but they suffer the reclassification risk (see the coefficient of the 10 year contract without requalifying). ${ }^{30}$

The estimate show that the 20-year level contract has a present value approximately $6 \%$ higher than the requalifiers' in a S\&U. ${ }^{31}$ This suggests: first, that the level contract is very close to achieving consumer commitment, as there is very little room to improve on the health pool kept under this contract. In other words, no much ratcheting can be taking place given the low gap in costs. Second, non-requalification happens with low probability; otherwise the gap between the level contract and the requalifying S\&U ART would be wider even if the longer contract kept the whole pool of individuals. Reclassification risk seems to be mostly overcome by locking-into long term level-premium contracts.

Aggregate contracts are less front-loaded than a level contract, but are non-state contingent, hence one would expect them to lie between the requalifying and non-requalifying: contracts, and they are. The last two columns show results for age 40 only. Qualitative results are unchanged, showing that results are not driven by differences across ages.

Contract Slopes (front-loading) and Present Values One way of comparing different types of contracts is by looking at contract dummies from the previous table. An alternative way is to relate slopes and premiums more directly. To do this, we proxy the slope of the premium profile by the ratio of the first over the 11 th premium, $\mathrm{Q}(1 \mathrm{st}) / \mathrm{Q}(11 \mathrm{th})$. Table 5 shows basic statistics for 40 years old policy holders. Note the wide range of both slopes and present values.

A higher $\mathrm{Q}(1 \mathrm{st}) / \mathrm{Q}(11 \mathrm{th})$ ratio means more is paid up-front. According to the model we expect contracts with a higher $\mathrm{Q}(1 \mathrm{st}) / \mathrm{Q}(11 \mathrm{th})$ ratio to keep a better pool of policy holders, hence a lower cost of insurance. We want to check how much of the variability in present

\footnotetext{
${ }^{30}$ Recall that different contracts appeal to individuals with different income profiles, i.e., it is not the case that some of the contracts are dominated.

${ }^{31}$ The dependent variable is in logs, for small coefficients the estimates represent percentual changes.
} 
values is explained by contract slopes.

\begin{tabular}{|c|c|c|c|c|}
\hline \multicolumn{5}{|c|}{ Table 5 } \\
\hline & Mean & Std Div & Min & Max \\
\hline $\mathrm{Q}(1$ st $) / \mathrm{Q}(11$ th $)$ & 0.42 & 0.31 & 0.04 & 1.00 \\
\hline $\mathrm{PV}$ & 15,779 & 8,376 & 6,044 & 63,807 \\
\hline $\ln (\mathrm{PV})$ & 9.56 & 0.46 & 8.71 & 11.06 \\
\hline
\end{tabular}

The first column of Table 6 presents the regression of the $\log$ of the present value of the premiums on the $\mathrm{Q}(1 \mathrm{st}) / \mathrm{Q}(11 \mathrm{th})$ ratio and other contract characteristics. The frontloading variable is highly significant; it actually explains most of the variability in premiums (excluding it from the regression drops the $\mathrm{R}^{2}$ from $73 \%$ to $3.6 \%$, see column 2 ). The third column presents a similar regression after omitting the twenty year contract from the sample. We do so to check whether these contracts, which have no variability in $\mathrm{Q}(1 \mathrm{st}) / \mathrm{Q}(11 \mathrm{th})$, were responsible for the negative relation between premiums and slope. The negative relation is still strong among the rest of the contracts as well. Columns 4 and 5 repeat the exercise for a sample of 5 and 10 nonrequalifying contracts and for aggregate ARTs respectively. The negative relation is confirmed.

The sixth column presents a similar regression for requalifying contracts. The theory predicts no relation between costs and slope for this contracts since Q(11th) just reflects the underwriting stringency, not the quality of the remaining pool. We present this regression as a control, to make sure there is nothing intrinsic to premiums creating the negative relation just reported. We find no statistically significant relation. 


\begin{tabular}{|c|c|c|c|c|c|c|}
\hline \multicolumn{7}{|c|}{ Table 6} \\
\hline & \multicolumn{6}{|c|}{$\log (\mathrm{PV})$} \\
\hline & (1) & (2) & (3) & (4) & (5) & (6) \\
\hline \multirow{2}{*}{$\mathrm{Q}(1 \mathrm{st}) / \mathrm{Q}(11 \mathrm{th})$} & -1.24 & - & -2.28 & -2.36 & -4.61 & 0.61 \\
\hline & $(-12.29)$ & - & $(-8.20)$ & $(-6.59)$ & $(-2.60)$ & $(1.60)$ \\
\hline \multirow[t]{2}{*}{ Renew } & .004 & 0.01 & .001 & -0.004 & 0.003 & 0.00 \\
\hline & $(1.02)$ & $(1.43)$ & $(0.14)$ & $(-0.54)$ & $(0.37)$ & 0.00 \\
\hline \multirow[t]{2}{*}{ Convert } & .003 & .0001 & -.005 & -0.004 & 0.003 & -0.01 \\
\hline & $(0.64)$ & $(0.11)$ & $(-0.90)$ & $(-0.53)$ & $(0.19)$ & $(-1.45)$ \\
\hline \multirow[t]{2}{*}{ Spec Restr } & 0.04 & 0.03 & -0.07 & -0.06 & - & -0.06 \\
\hline & $(0.28)$ & $(0.11)$ & $(-0.48)$ & $(-0.45)$ & - & $(-0.50)$ \\
\hline \multirow[t]{2}{*}{ Constant } & 9.96 & 9.29 & 10.35 & 10.47 & 11.43 & 8.90 \\
\hline & $(87.2)$ & $(49.75)$ & $(65.9)$ & $(48.26)$ & 13.39 & 45.14 \\
\hline $\mathrm{R}^{2}$ & 72.6 & 3.6 & 64.5 & 56.7 & 45.5 & 14.5 \\
\hline $\mathrm{N}$ & 65 & 65 & 53 & 40 & 13 & 38 \\
\hline \multicolumn{7}{|c|}{ Sample includes 40 year old individuals, t-statistic in parenthesis } \\
\hline
\end{tabular}

\subsection{Front-loading and Lapsation}

The role of front-loading as a device to provide more insurance depends on locking-in consumers. According to the theory, the force that generates lower cost for more front-loaded contracts involves more health related lapsation for less front-loaded contracts.

Table 7 presents lapsation figures, from LIMRA (Life Insurance Marketing Research Association, Inc.) (1996), for ARTs versus (longer) Term contracts. Recall that ARTs are less front-loaded than longer term contracts. This data is not ideal since it does not provide a complete break down of lapsation by type of contract. It only allows us to contrast ARTs with term contracts of longer length (includes 3 to 30 year level contracts). Unfortunately, we do not have data that provides a more detailed break-down of lapsation figures.

The first two columns present lapsation as a percent of face amount. It confirms Proposition 2. Aside from the first year of the contract, where not much lock-in has occurred, longer contracts have lower lapsation, and a steeper decline over time. A similar picture appears in the next two columns, that report lapsation as a percent of the number of policies.

The second part of the table separates lapsation by age groups. More health related information revelation is likely to occur in the 40-59 age-groups than in the 20-39. We find, as we would expect, that the difference in lapsation between ART and Term is bigger for the 
older group, namely, when most of the learning takes place.

\begin{tabular}{|c|c|c|c|c|c|c|c|c|}
\hline \multicolumn{9}{|c|}{ Table 7} \\
\hline & \multicolumn{2}{|c|}{$\%$ of FaceAmnt } & \multicolumn{2}{|c|}{$\%$ of policies } & \multicolumn{4}{|c|}{$\%$ of Face Amount } \\
\hline & ART & Term & ART & Term & ART & Term & ART & Term \\
\hline Contract Year & & & & & \multicolumn{2}{|c|}{ Ages 20-39 } & \multicolumn{2}{|c|}{ Ages $40-59$} \\
\hline 1 & 11.8 & 14.2 & 15.0 & 21.2 & 14.3 & 18.2 & 14.4 & 10.8 \\
\hline 2 & 14.1 & 11.4 & 14.8 & 14.1 & 15.3 & 13.2 & 16.4 & 9.5 \\
\hline $3-5$ & 13.4 & 8.0 & 12.4 & 7.4 & 12.5 & 7.4 & 16.2 & 6.4 \\
\hline $6-10$ & 10.1 & 5.0 & 9.4 & 5.2 & 9.15 & 5.1 & 14.1 & 4.5 \\
\hline $11+$ & 7.0 & 3.9 & 6.5 & 3.8 & 7.0 & 4.05 & 9.8 & 3.9 \\
\hline
\end{tabular}

\section{$5 \quad$ Income Profiles}

One of the implications of the model that we have not yet explored empirically is the comparative statics with respect to the income slopes. This cannot be done directly with the available data. However, there is data that can be used for this issue if the model is extended to more periods. This is the LIMRA Buyers' study. The buyer's study is a survey of the policies that were recently issued by members of LIMRA. The unique feature of this data set is that it contains information on the type of life insurance policy purchased by the different individuals.

Fxtending the model is straightforward but notationally intensive. Thus, we only present the intuition. We can think of the first period death probability as $p_{i}^{1}$, that is, as the inherited health status, indexed by $i$. For every type $i$ at period 1 there is a continuation equilibrium identical to the one we characterized in section 2 , for $p=p_{i}^{1}$. At time 0 , contracts incorporate the subsequent contracts generated by each $p_{i}^{1}$. It easy to see that longer contracts involve the same trade-off between income allocation and reclassification risk. The extension enables us to think about different income slopes at different stages. For instance, workers with higher education expect income increases early in life, followed by a flatter income path. In contrast, blue collar workers face a flatter profile all the way.

This extension suggests a test of the model that uses a comparison of the extent of contract front-loading chosen by individuals at different stages in life, or by individuals with different income profiles. For the population as a whole, we expect an increase in frontloading (as income rises and then flattens). We also expect that, the steeper the income growth in early stages, the more pronounced the difference between early and later contracts. 
This suggests doctors and lawyers, for whom income growth is steeper early in their lives, should experience the largest move towards front-loaded contracts over time. In contrast, front-loading is not expected to change if either the individual does not to expect income increases or if the individual has access to capital from early stages in life.

We use the LIMRA Buyers Study to test these predictions. The Buyers Study is a survey of recently issued policies by the main members of LIMRA. Although not ideal for our purposes (as it does not follow a specific buyer over time and the sample is not the stock of holders but the flow of buyers) the Buyer's study has a very important piece of information. It reports the type of life insurance contract purchased, i.e.: ART, LT20, etc. ${ }^{32}$

The population as a whole shows a move towards more front-loaded contracts after the age of 40 (see Table 8). This can be seen by comparing the "Mean" which is the mean category, computed by defining ART as 1, LT5 as 2, LT10 as a 3, LT15 as a 4, and LT20 as a $5 .{ }^{33}$ Furthermore, the second column first order stochastically dominates the first. The $\chi^{2}$ test (reported in the last row) rejects the null that the two columns represent the same proportions.

The second part of the exercise involves a comparison of the contracts chosen by consumers in different professions.

LIMRA classifies each term insurance buyer into one of 95 professions, most of them present only a few observations. We chose doctors (broadly defined) and managers as an example of steep income in early stages, followed by a flatter period. We chose blue collar workers (laborers) as a case of stable lifetime income; this should translate into small or no changes toward front-loading over time. ${ }^{34}$

\footnotetext{
${ }^{32}$ We restrict to male buyers as their income profile is more likely to determine the household's main source of income.

${ }^{33}$ This is just a way to translate categorical data into a single index, in spite of the categories not having a well defined cardinal relation. Alternative specifications would give similar results.

${ }^{34}$ We confirmed the steepness of income profiles of doctors, managers and laborers using the income reported by each profession by age. Although there is a very low number of respondents who report income, the available figures are: income above 40 is higher than income below 35 for all groups, $269 \%$ for doctors, $253 \%$ for managers, $209 \%$ for business owners and only $16 \%$ for laborers.
} 


\begin{tabular}{|c|c|c|}
\hline \multicolumn{3}{|c|}{ Table 8} \\
\hline & Whole Sample \\
\hline & Age $\leq 35$ & Age $\geq 40$ \\
\hline \hline ART & 27.9 & 18.2 \\
\hline LT5 & 36.2 & 30.3 \\
\hline LT10 & 20.1 & 26.2 \\
\hline LT15 & 3.4 & 10.9 \\
\hline LT20 & 12.4 & 14.3 \\
\hline \hline Mean & 2.36 & 2.73 \\
\hline Obs. & 2747 & 2650 \\
\hline$\chi^{2}$ & \multicolumn{3}{|c|}{607.6} \\
\hline Share of contracts by type. \\
\hline
\end{tabular}

We look at business owners because they presumably have easier access to capital, hence should be front-loaded starting in the early periods. ${ }^{35}$

In Table 9 we present the shares of different types of contracts by profession and age. ${ }^{36}$ Comparing means we see that doctors are the profession that moves the most to frontloading over time, while laborers moves the least. This is consistent with doctors expecting the steepest income increase in the early period and laborers expecting the lowest income increase. The $\chi^{2}$ test compares each group to the same age for the whole sample. ${ }^{37}$

Interestingly, the most front-loaded in the early period are business owners who presumably have access to capital in the early period. Managers show a slightly larger move toward front-loading than the whole sample.

\footnotetext{
${ }^{35}$ Due to the low number of observations per classification we aggregated some professions. Doctors include: Physicians, dentists, architects, lawyers, judges, scientists, pharmacists, veterinarians and engineers. Managers include government officials, retail, manufacturing, school and utility managers. Laborer is a very broad class including most blue collar workers.

${ }^{36} \mathrm{~A}$ potential concern is that different profession have different access to life insurance, possibly through plans offered in the workplace. If that was the case, for some professions the numbers we report may only reflect supplementary coverage, potentially with different characteristics. Although we cannot rule this concern out, the ratio of coverage over income is very similar across profession, and around 5, suggesting that purchases reported in LIMRA are likely to be the main source of insurance.

${ }^{37}$ The critical value to reject independence at the $5 \%$ level is 9.49 .
} 


\begin{tabular}{|c|c|c|c|c|c|c|c|c|}
\hline \multicolumn{10}{|c|}{ Table 9} \\
\hline & Doctors & \multicolumn{1}{|c|}{ Managers } & \multicolumn{2}{|c|}{ Laborers } & \multicolumn{2}{c|}{ Business Owners } \\
\hline Age & $\leq 35$ & $\geq 40$ & $\leq 35$ & $\geq 40$ & $\leq 35$ & $\geq 40$ & $\leq 35$ & $\geq 40$ \\
\hline \hline ART & 34.9 & 19.1 & 20.0 & 13.3 & 22.2 & 22.4 & 7.7 & 12.7 \\
\hline LT5 & 20.9 & 6.4 & 43.3 & 26.6 & 33.3 & 29.9 & 0 & 6.3 \\
\hline LT10 & 23.3 & 34.5 & 20.0 & 32.3 & 27.8 & 31.3 & 53.8 & 39.7 \\
\hline LT15 & 7.0 & 29.1 & 10.0 & 20.9 & 4.2 & 10.4 & 19.2 & 19.0 \\
\hline LT20 & 14.0 & 10.9 & 6.7 & 7.0 & 12.5 & 6.0 & 19.2 & 22.2 \\
\hline \hline Mean & 2.44 & 3.06 & 2.40 & 2.82 & 2.51 & 2.48 & 3.42 & 3.32 \\
\hline Obs. & 43 & 110 & 90 & 158 & 72 & 67 & 26 & 121 \\
\hline$\chi^{2}$ & 5.3 & 58.1 & 16.8 & 25.4 & 3.2 & 4.6 & 47.8 & 81.2 \\
\hline Proportions of contracts by type for different professions/ages. \\
\hline
\end{tabular}

\section{Alternative Explanations}

In this section we explore and attempt to rule out alternative potential explanations for the of the empirical findings discussed above.

(1) Commissions: Longer term contracts may involve lower commissions hence lower costs. We do not think this explains the observed relation. There is no economic reason for rewarding agents more for selling contracts with higher lapsation. We verified this with insurance agents who reported that longer term contracts do not involve lower commissions.

(2) Fixed Underwriting Costs: Underwriting involves fixed costs. Because longer term contracts have lower lapsation, these fixed costs are incurred less frequently. This would explain the lower present value of premiums of longer contracts.

If this hypothesis was correct, then the savings from longer term contracts would decline in the face amount of the policy since the fixed cost would become relatively less important. Table 10 compares different levels of coverage, from $100,000 \$$ to 10 million dollars. In every case the same pattern arises. The ratio of present values (of 20 years of coverage) of an ART over a LT20 does not decline in face amount. Thus, this explanation does not appear to adequately account for the observed phenomena. 


\begin{tabular}{|l|c|c|c|c|c|}
\hline \multicolumn{6}{|c|}{ Table 10: Costs and Size of the Policy } \\
\hline & NW & Jackson & TranAm & USAA & Metro \\
\hline Policy Amt & \multicolumn{6}{|c|}{ Ratio ART/LT20 } \\
\hline $100 \mathrm{~K}$ & 1.14 & 2.21 & 2.44 & 1.18 & 1.07 \\
\hline 1 Million & 1.23 & 2.82 & 2.44 & 1.16 & 1.17 \\
\hline 10 Million & 1.24 & 2.89 & 2.44 & 1.18 & 1.17 \\
\hline
\end{tabular}

(3) Cross Firm Differences in Underwriting Standards: It is possible that firms specialize in specific types of contracts, and that those firms offering longer contracts at the same time perform more strict underwriting. Again, this would explain the relation between premiums and length of the contract. To test this hypothesis we compared within firms contract costs, by: first, running the regression in Table 4 with firm effects. Results are unchanged from the previous analysis. Second, we computed ratios of ART and LT20 cost, as in table 10, for all firms offering both ARTs and LT20s. For every firm, and for almost every age the ratio is higher than 1 confirming this happens within firms as well. ${ }^{38}$

(4) Accidental Death, a Test Case: Something intrinsic to the selling of insurance may lead to this pricing behavior. To evaluate this hypothesis we look at Accidental Death Insurance. It is a similar good with the exception that it only pays if death is accidental, i.e., it is not health related. Death rates from accidental death are quite flat between the ages of 25 to 60 and firms are unlikely to learn much about the characteristics of the consumers, which we argued is the driving force behind our results. Thus, we expect the predictions of the model to have less of a bite. In other words there is no reason to predict that frontloading will be used to improve long-run insurance. We found that both the probability of an accident and premiums are flat between ages 25 to 60 , so that there is no front-loading. Actually, all the quotes we found on the web are age independent.

Thus, a very similar product which involves less learning about risk characteristics displays no front-loading and no relation between present values and front-loading; this can be viewed as an experiment whereby removing the key assumption about learning makes the main prediction disappear from the data.

(5) Correlation Mortality-Income: since mortality and income are negatively correlated, the lower cost of more front-loaded contracts could be caused by higher income consumers purchasing those contracts. This explanation can be ruled out by using Table 10. If income levels (through the correlation with mortality) were creating the link between

\footnotetext{
${ }^{38}$ One company had exceptions for young ages if a high discount factor is used.
} 
front-loading and present value, then that relation should disappear as the face amount becomes very large since only the very rich will buy a 10 million policy.

(6) Search Costs and heterogeneous need for insurance: We have already mentioned in section 2.4 that additional factors may influence consumers' contract choices and the possibility of lapsation: e.g., uncertainty about the need for insurance or about the duration of this need. However, if lapsation is not associated with learning about the health status, the observed negative relation between front-loading and present value of costs of insurance would be absent.

One can also think of consumers being heterogeneous in their propensity to search for new policies. One could then interpret a steep premium profile as an attempt to profit from consumers who do not search. Consumers who search drop their coverage, those that do not end up overpaying. This hypothesis can be incorporated into the model, and it would be consistent with some of the findings. Perhaps this phenomenon might contribute to the relations we find. However, it cannot be the major force behind the findings. First, under competition the positive profits in the long run from low search consumers has to be compensated by losses early in the contract. This contradicts the findings in Table 2, where we reported that front-loading is present in all contract types. Second, since insurance agents profit from replacing policies, they would have an incentive to let consumers know that they can save if they requalify. Finally, incentives to search increase in the face amount, hence, we would expect the negative relation between cost and slope to disappear as policy values increase. As we saw in Table 10 it does not.

\section{Concluding Remarks}

Having argued that the contracts offered in the life insurance market fit the theoretical predictions of a model with one-sided commitment, we are left to answer the empirical question of the extent of the welfare distortions. To what extent is commitment by consumers achieved, by locking into long-term level contracts?

This question is of particular relevance in light of the Health Insurance debate. Guaranteed renewability has been proposed (for instance, as one element in Clinton's health care proposed reform) as a necessary condition to assure universal health insurance coverage. At the same time, guaranteed renewability has been criticized (Cochrane (1995)) as insufficient or ineffective due to lack of consumer commitment.

We learn from the Life Insurance Industry: First, in spite of the lack of consumer com- 
mitment most households have access to life insurance. Hence, the ability of firms to commit to guarantee renewability seems to be enough to assure access to long term insurance. It is interesting to note that insurance companies offer guaranteed renewable contracts without the need of any regulatory imposition. Second, according to our numbers, some of the commonly purchased term contracts come very close to capturing all the gains from long term insurance, consumers are left to suffer very little reclassification risk (see section ??). It should be noted that this achievement comes at a cost because it requires consumers to pay more up front than would be optimal from the point of view of intertemporal consumption smoothing. However, according to our estimates this cost is low, probably too low to grant market intervention.

According to our analysis the life insurance industry copes with the problem of lack of consumer commitment contracts by offering front-loaded contracts, which reduce reclassification risk (enhance commitment). The life insurance experience is sharply in contrast with the health insurance one where front-loaded contracts are not offered and reclassification risk is a major concern.

What makes the performance of these two industries so different? What other features of the health insurance market interact with the lack of consumer commitment to create inefficiencies not observed in the life insurance market?

There are several differences between these markets: First, while life insurance is about insuring an income stream, health insurance is about health care treatment. Thus, the amount needed to be front-loaded to generate long term insurance is proportional to income in the life insurance market while independent of income in the health insurance market. Hence, health insurance front-loading is likely to be unaffordable to low income households. Second, treatment cost risk is non-diversifiable, since it affects all patients (for more on this argument see Cutler (1992)). Finally, health insurance involves a quality of service, susceptible to moral hazard on the part of insurance companies (in particular, under managed care). Hence, consumers are likely to be more reluctant to lock-in to a health insurer, who later on can reduce quality.

\section{Appendix}

\section{Proof of Proposition 1}

Proof: Let $\mu$ be the Lagrange multiplier for the constraint in (3) and $\lambda_{i}$ the Lagrange multiplier for the ith constraint in (4).

From the first order conditions for an optimum are: 


$$
\begin{gathered}
u^{\prime}\left(y-g-Q_{1}\right)=\mu \\
v^{\prime}\left(F_{1}\right)=\mu \\
-(1-p) q_{i} u^{\prime}\left(y+g-Q_{2}^{i}\right)+(1-p) q_{i} \mu+\lambda_{i}=0 \\
(1-p) q_{i} v^{\prime}\left(F_{2}^{i}\right)-(1-p) q_{i} \mu-\lambda_{i}=0 \\
\left(\left(1-p_{i}\right) Q_{2}^{i}-p_{i} F_{2}^{i}\right) \lambda_{i}=0
\end{gathered}
$$

Combining equations (7) and (8) we obtain the result of part(ii). Analogously, combining equations (9) and (10) we obtain the result of part (i).

\section{Proof of Proposition 2}

Proof: The fact that there is full insurance in every state and at date 1 implies that for every state $i$, we have: $F_{2}^{i}=\left(v^{\prime}\right)^{-1}\left(u^{\prime}\left(y+g-Q_{2}^{i}\right)\right)$. Analogously, at date 1 we have $F_{1}=\left(v^{\prime}\right)^{-1}\left(u^{\prime}\left(y-g-Q_{1}\right)\right)$. This imposes a relation between the face value and the premium.

Step (1). We want to show that there is an $s$ such that the constraints 1 through $s$ in (4) are binding, the constraints $s+1$ through $N$ are not, and $Q_{2}^{1}<\ldots<Q_{2}^{s}=\ldots=Q_{2}^{N}$. Observe first that if $i$ and $j$ are two binding constraints, we obtain that if $i<j, Q_{2}^{i}<Q_{2}^{j}$ by implicitly differentiating with respect to $p$ the full insurance condition, and by substituting the fair premium. Thus, the set of binding constraints is ordered. Suppose now that $i<j$, $Q_{2}^{i}>Q_{2}^{j}$. Then constraint $j$ must be non binding. Let $Q^{M}$ be the highest premium. It is then possible to reduce $Q^{M}$ and increase $Q_{2}^{j}$ without violating either the two constraints or the budget constraint. This is a transfer of money at period 1 from the state with the higher premium to the state with the lower premium that does not involve any transfer of resources from the first period to the second period. In a zero profit equilibrium this transfer occurs at a fair rate and improves the smoothing of consumption across health states.

We now show that some of the constraints in equation (4) must be non binding. Note that, substituting from equation (7) into equation (9), we obtain:

$$
u^{\prime}\left(y+g-Q_{2}^{i}\right)=u^{\prime}\left(y-g-Q_{1}\right)-\frac{\lambda_{i}}{(1-p) q_{i}}
$$


Suppose that all constraints were binding. Then, from equation $(12), Q_{2}^{N}(F I)-Q_{1}(F I)<$ $2 g$ which cannot happen if $p_{N}$ is large relative to $p$ or if $g$ is not too large. If $p_{N}$ and $p_{N-1}$ are close, then $Q_{2}^{N}=Q_{2}^{N-1}$ so that there is at least some pooling in the second period. These steps prove parts (i) and (ii).

Part (iii) is obvious: as $g$ increases more and more constraints are going to be binding. This means that, as $g$ grows, $s$ becomes larger. When $s$ is larger, $Q_{1}$ declines.

\section{Bibliography}

Best's Review. "The Industry Responds", September 1979.

Black, K. and H. Skipper. "Life Insurance," Prentice Hall, Englewood Cliffs, NJ,1994.

Brugiavini, A. (1990) "Longevity Risk and the Life Cycle." Ph.D. Dissertation, LSE, London.

Cawley J.; Philipson T.(1998) “An Empirical Examination of Information Barriers to Trade in Insurance."

Chiappori, P.A. (1998) "Econometric Models of Insurance under Asymmetric Information." Handbook of Insurance edited by Georges Dionne, forthcoming.

Chiappori, P.A.; Macho, I; Rey, P. ; Salanie', B. (1994) "Repeated Moral Hazard: Memory, Commitment, and the Access to Credit Markets." European Economic Review. pp. $1527-53$.

Chiappori, P.A.; Salanie', B.; Valentin, J. (1998). "Early Starters Versus Late Beginners." Journal of Political Economy, forthcoming.

Cochrane, J. (1995) "Time Consistent Health Insurance." Journal of Political Economy. Vol. 103, pp. 445-473.

Crocker, K. and J. Moran. (1998) "Contracting with Limited Commitment: Evidence from Employment Based Insurance Contracts." mimeo University of Michigan.

Cutler, D. (1993) "Why Doesn't the Market Fully Insure Long term Care." NBER WP 4301.

Daily, G. (1989), The Individuals Investor's Guide to Low-Load Insurance Products by International Publishing Corp. 
Diamond, P. (1992) "Organizing the Health Insurance Market." Econometrica. Vol. 60. pp. $1233-54$.

Dionne, G. and Doherty, M. (1992) "Adverse Selection in Insurance Markets, A Selective Survey" in Contributions to Insurance Economics edited by Georges Dionne, Kluwer Academic Press.

Dionne, G. and Doherty, M. (1994) "Adverse Selection, Commitment and Renegotiation: Extension to and Evidence from Insurance Markets." Journal of Political Economy pp. 210-235.

Dukes, J. and MacDonald, A. (1980) "Pricing a Select and Ultimate Annual Renewable Term Product" Transactions of the Society of Actuaries, VolXXXII, pp. 547-567.

Federal Trade Commission Staff Report on Life Insurance Cost Disclosure, July 1979.

Friedman, B.M.; Warshawski, M.J. (1990) "The Cost of Annuities: Implications for Savings Behavior and Bequests." Quarterly Journal of Economics. pp. 135-154.

Fudenberg, D.; Holmstrom, B; Milgrom, P. (1990) "Short Term Contracts and Long Term Agency Relationship." Journal of Economic Theory. pp. 1-31.

De Garidel T. (1998) "Pareto Improving Asymmetric Information in a Dynamic Insurance Market." Mimeo, UCL.

Harris, M.; Holmstrom, B. (1982) "A Theory of Wage Dynamics." Review of Economic Studies. Vol. 49, pp 315-333.

Jaffe, Jay M. (1998). "Accidental death Experience: A Review of recent Experience for the Practicing Actuary," mimeo.

Life Insurance Fact Book, American Council of Life Insurance, several issues.

LIMRA, "Long-Term Ordinary Lapse Survey-U.S.", Connecticut 1996.

LIMRA, "Buyer's Study", Connecticut 1997.

McGill, D. Life Insurance, Richard D. Irwing, 1967.

Murphy, K. (1986) "Incentives, Learning, and Compensation: A Theoretical and Empirical Investigation of Managerial Labor Contracts." Rand Journal of Economics. Vol. 17, pp. 59-76. 
Pauly, M.; Kunreuther, H.; Hirth R. (1995) "Guaranteed Renewability in Insurance." Journal of Risk and Uncertainty. Vol. 10. pp. 143-156.

Society of Actuaries: Report on Preferred Underwriting, 1995.

Villeneuve, Bertrand (1999) "Life Insurance" in Handbook of Insurance, edited by Georges Dionne, forthcoming. 